\title{
ARTICLE OPEN \\ Local delivery of arsenic trioxide nanoparticles for hepatocellular carcinoma treatment
}

\author{
Jian Hu${ }^{1}$, Yi Dong ${ }^{2}$, Li Ding ${ }^{1}$, Yang Dong ${ }^{1}$, Zhihua Wu ${ }^{1}$, Wenping Wang ${ }^{2}$, Ming Shen ${ }^{1}$ and Yourong Duan ${ }^{1}$
}

Hepatocellular carcinoma (HCC) is a malignancy with a poor prognosis. Surgery combined with chemotherapy has been recommended as a curative regimen for HCC. Nevertheless, the anticancer mechanisms of chemicals in hepatocellular carcinoma remain unclear. Pyroptosis is a type of programmed necrosis, and its mechanism in hepatocellular carcinoma is poorly understood. The efficacy and mechanism of arsenic trioxide nanoparticles in the treatment of HCC were explored in this research. Arsenic trioxide alone and arsenic trioxide nanoparticles were conveniently administered to mice intratumorally using a needle. Compared with $\mathrm{As}_{2} \mathrm{O}_{3}, \mathrm{As}_{2} \mathrm{O}_{3}$ nanoparticles $\left(\mathrm{As}_{2} \mathrm{O}_{3}\right.$-NPs) showed better inhibition, promoted greater $\mathrm{LDH}$ release, and induced cell morphology indicative of pyroptosis in vitro. Compared with the free drug, $\mathrm{As}_{2} \mathrm{O}_{3}-\mathrm{NPs}$ increased GSDME-N expression and decreased Dnmt3a, Dnmt3b, and Dnmt1 expression in Huh7 cells. In vivo, $\mathrm{As}_{2} \mathrm{O}_{3}-\mathrm{NPs}$ induced a significant decrease in the expression of Dnmt3a, Dnmt3b and Dnmt1, but significantly upregulated the expression of GSDME-N (gasdermin E (GSDME) was originally found to be related to deafness; recently, it has been defined as a gasdermin family member associated with pyroptosis). $\mathrm{As}_{2} \mathrm{O}_{3}-\mathrm{NPs}$ inhibited tumor growth more strongly than $\mathrm{As}_{2} \mathrm{O}_{3}$ or control, a finding likely attributed to the downregulation of PCNA and DNMT-related proteins and the upregulation of GSDME-N.

Signal Transduction and Targeted Therapy (2019)4:28; https://doi.org/10.1038/s41392-019-0062-9

\section{INTRODUCTION}

Hepatocellular carcinoma ( $\mathrm{HCC}$ ) is a malignancy with a poor prognosis, and an considerable medical challenge. 'Surgery is an option to remove or even eliminate the tumor as first-line therapy for cancer patients. A patient can subsequently receive systemic chemotherapy to eliminate residual cancer after surgery, and to keep the cancer from returning.

Many chemotherapeutic agents are used in the clinic. Arsenic trioxide has been used alone and in combination as drug therapy for acute promyelocytic leukemia., ${ }^{2,3}$ In addition, there has been constant progress in applying arsenic trioxide treatment for solid tumors, including $\mathrm{HCC}^{4-7} \mathrm{As}_{2} \mathrm{O}_{3}$ can promote the differentiation of surviving cancer cells. This characteristic allows $\mathrm{As}_{2} \mathrm{O}_{3}$ to reduce the malignant behavior and metastatic risk of surviving cancer cells during chemotherapy, achieving better treatment responses with lower rates of metastasis and recurrence than traditional anticancer drugs. ${ }^{8}$ However, it is difficult to achieve effective $\mathrm{As}_{2} \mathrm{O}_{3}$ accumulation inside a solid tumor because of rapid clearance of this drug in blood circulation., ${ }^{9,10}$ A high dose can be used to maintain the therapeutic activity but causes systemic adverse reactions. Many studies have aimed to determine how to maintain a therapeutic $\mathrm{As}_{2} \mathrm{O}_{3}$ concentration within target solid tumor tissue for an extended period of time with few systemic adverse reactions has been the aim of the most studies. Localized chemotherapy may be an alternative treatment modality. Much attention has been focused on localized chemotherapy, such as a direct intratumoral injection. ${ }^{11,12}$ Local drug delivery systems can prolong the retention time of chemotherapeutic agents at the dosing site to obtain more continuous efficacy and reduce adverse reactions in normal organs and tissues. ${ }^{13-17}$

In the current study, we used mPEG-PLGA-PLL triblock copolymers with cationic amine groups and hydrophobic/hydrophilic chains, which are suitable for carrying drugs. ${ }^{18,19}$ Furthermore, the degradation products of these copolymers are nontoxic to cells. ${ }^{20}$ This study aimed to investigate the nano drug delivery system mPEG-PLGA-PLL loaded with arsenic trioxide, which was delivered via intratumoral administration.

$\mathrm{As}_{2} \mathrm{O}_{3}$ exerts antitumor effects through several mechanisms of action, including the induction of G2/M arrest and apoptosis, ${ }^{4,21}$ but pyroptosis has not been studied in this context. Pyroptosis was originally identified as caspase 1-triggered cell death associated with innate immune defense against microbial infection. In addition, cell death can be induced by caspases $11 / 4 / 5$, which cleave gasdermin D (GSDMD is a member of the gasdermin family. Gasdermin D has been suggested to act as a tumor suppressor and pyroptosis executor) to trigger pyroptosis. ${ }^{22,23}$ The characteristics of pyroptosis include membrane pore formation, cellular bulging, proinflammatory factor release and cytolysis. ${ }^{24-28}$ GSDME/DFNA5 was originally found to be related to deafness; recently, it has been defined as a gasdermin family member associated with pyroptosis. ${ }^{25}$ GSDME is a pyroptosis execution molecule activated by cleaved caspase 3 after treatment with a proapoptotic agent, such as a chemical drug, that has similar function to GSDMD in membrane pore formation. ${ }^{24,25}$ In this study, we evaluated pyroptosis of Huh7 and HepG2 cells induced by arsenic trioxide formulations for the first time.

\footnotetext{
${ }^{1}$ State Key Laboratory of Oncogenes and Related Genes, Shanghai Cancer Institute, Renji Hospital, School of Medicine, Shanghai Jiao Tong University, 200032 Shanghai, China and ${ }^{2}$ Department of Ultrasound, Zhongshan Hospital, Fudan University, 200032 Shanghai, China

Correspondence: Ming Shen (mshen@shsci.org) or Yourong Duan (yrduan@shsci.org)
}

Received: 19 January 2019 Revised: 28 May 2019 Accepted: 20 June 2019

Published online: 06 September 2019 
a

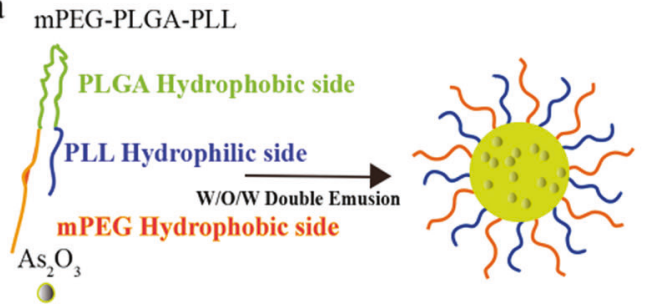

0

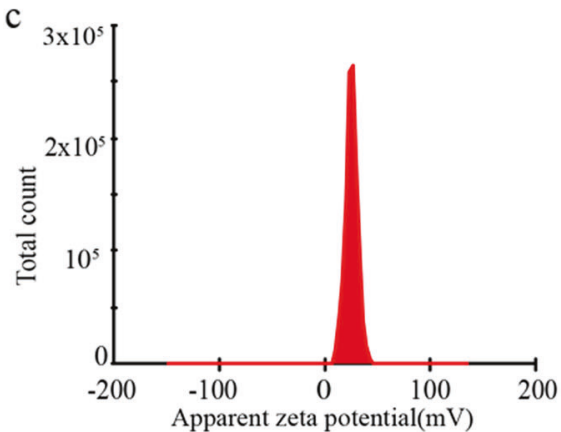

b

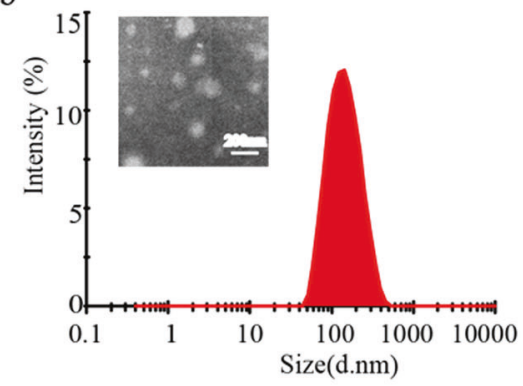

d

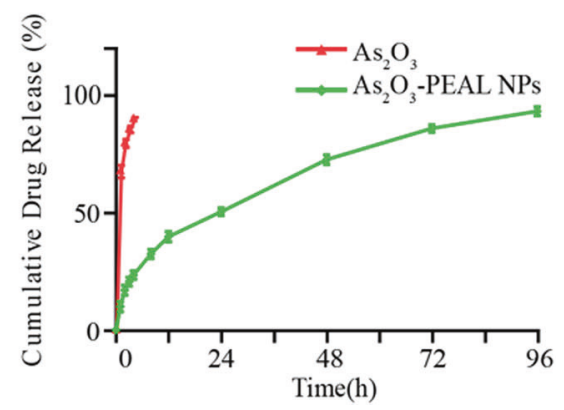

Fig. 1 Preparation and characterization of $\mathrm{As}_{2} \mathrm{O}_{3}-\mathrm{NPs}$. a Schematic illustration of the formulation of $\mathrm{As}_{2} \mathrm{O}_{3}-\mathrm{NPs}$. $\mathbf{b}$ Size distribution and TEM image of $\mathrm{As}_{2} \mathrm{O}_{3}$-NPs. c Zeta potential of $\mathrm{As}_{2} \mathrm{O}_{3}$-NPs. d Release profile of free $\mathrm{As}_{2} \mathrm{O}_{3}$ and $\mathrm{As}_{2} \mathrm{O}_{3}-\mathrm{NPs}$

\section{RESULTS}

Preparation and characterization of nanoparticles

A double-emulsion method was used to prepare $\mathrm{As}_{2} \mathrm{O}_{3}-\mathrm{NPs}$ (Fig. 1a). The particle size and PDI (Polymer dispersity index) were $127.5 \pm$ 0.88 and $0.21 \pm 0.004$, respectively (Fig. 1 b). The zeta potential was $26.2 \pm 1.42$ (Fig. 1c). As shown in the transmission electron microscopy (TEM) image, the $\mathrm{As}_{2} \mathrm{O}_{3}-\mathrm{PEAL}$ NPs were spherical without aggregation, and the nanoparticle size results were consistent with the DLS results. The loading capacity (DL\%) and drug encapsulation efficiency (EE\%) of $\mathrm{As}_{2} \mathrm{O}_{3}$-PEAL NPs as measured by ICP were $5.8 \%$ and $72 \%$, respectively. The release rate of $\mathrm{As}_{2} \mathrm{O}_{3}$ from $\mathrm{As}_{2} \mathrm{O}_{3}-\mathrm{NPs}$ was much slower than that of free $\mathrm{As}_{2} \mathrm{O}_{3}$ (Fig. 1d).

\section{$\mathrm{As}_{2} \mathrm{O}_{3}-\mathrm{NPs}$ induce $\mathrm{HCC}$ pyroptosis}

The anticancer effects of $\mathrm{As}_{2} \mathrm{O}_{3}$ were evaluated in the HCC cell lines Huh7 and Bel-7402 (Figs. S2 and S4). Consistently, Huh7 and Bel-7402 cell death was triggered by $\mathrm{As}_{2} \mathrm{O}_{3}$ in a dose-dependent manner. Lactate dehydrogenase $(\mathrm{LDH})$ release was significantly increased in both cell lines with the increase in $\mathrm{As}_{2} \mathrm{O}_{3}$ dose. More dying cells with blebs were observed by phase-contrast microscopy as the dose increased. The $\mathrm{As}_{2} \mathrm{O}_{3}$-NP preparation method was similar to previously reported methods. $\mathrm{As}_{2} \mathrm{O}_{3}-\mathrm{NP}$ treatment triggered more blebbing cells than free $\mathrm{As}_{2} \mathrm{O}_{3}$ (Fig. 2a). Notably, the $\mathrm{LDH}$ release was significantly increased in Huh7 and HepG2 cells treated with $\mathrm{As}_{2} \mathrm{O}_{3}-\mathrm{NPs}$ compared with free $\mathrm{As}_{2} \mathrm{O}_{3}$ (Fig. 2b, c). The $\mathrm{LDH}$ release indicated that $\mathrm{As}_{2} \mathrm{O}_{3}$ destroyed the cell membrane integrity of the HCC cells. The above results showed that $\mathrm{As}_{2} \mathrm{O}_{3}$ treatment caused pyroptosis of $\mathrm{HCC}$ cells. The effective uptake of $\mathrm{As}_{2} \mathrm{O}_{3}$ into cells was probably responsible for the high cytotoxicity of $\mathrm{As}_{2} \mathrm{O}_{3}$-NPs. To confirm this hypothesis, we incubated Huh7 and HepG2 cells with free $\mathrm{As}_{2} \mathrm{O}_{3}$ and $\mathrm{As}_{2} \mathrm{O}_{3}-\mathrm{NPs}$ for $24 \mathrm{~h}$, and the cellular arsenic (As) uptake level was detected by ICP-MS. The cellular uptake level in the $\mathrm{As}_{2} \mathrm{O}_{3}-\mathrm{NP}$ group was nearly twofold higher than that in the $\mathrm{As}_{2} \mathrm{O}_{3}$ group.

Therapeutic mechanisms of $\mathrm{As}_{2} \mathrm{O}_{3}$-NPs in vitro

GSDME or GSDMD cleavage can free the N-terminal domain, which inserts into the membrane and triggers pyroptosis. The results indicated that GSDME cleavage was strongly triggered by the increase in $\mathrm{As}_{2} \mathrm{O}_{3}$ dose in Huh7 cells, while GSDMD was not detected by western blotting (Fig. S3). However, in Bel-7402 cells, GSDMD cleavage was induced by increasing doses of $\mathrm{As}_{2} \mathrm{O}_{3}$, and GSDME was not detected (Fig. S5).

Next, we explored the therapeutic mechanisms of nanoparticles packed with $\mathrm{As}_{2} \mathrm{O}_{3}$ in inducing pyroptosis. GSDME has a gasdermin- $\mathrm{N}$ domain capable of inducing pyroptosis in GSDMEexpressing cancer cells. GSDME is a key determinant of arsenic trioxide-induced pyroptosis in Huh7 and HepG2 cells. Full-length GSDME (GSDME-F) and N-terminal-cleaved GSDME (GSDME-N) protein levels were detected using western blotting. The results indicated that although both $\mathrm{As}_{2} \mathrm{O}_{3}-\mathrm{NPs}$ and free $\mathrm{As}_{2} \mathrm{O}_{3}$ increased GSDME-N protein levels, the effect of $\mathrm{As}_{2} \mathrm{O}_{3}-\mathrm{NPs}$ was more pronounced (Fig. 3). Caspase 3 cleavage was responsible for the $\mathrm{As}_{2} \mathrm{O}_{3}$-induced GSDME activation and pyroptosis. Cleaved caspase 3 levels were increased by $\mathrm{As}_{2} \mathrm{O}_{3}-\mathrm{NPs}$ compared with free $\mathrm{As}_{2} \mathrm{O}_{3}$.

Studies have shown that arsenic can induce DNA hypomethylation by consuming S-adenosylmethionine, the major cofactor for various methyltransferases, including DNMT, which is responsible for DNA methylation in cells. DNMT-related proteins are associated with patient prognosis and may play an important role in inducing the re-expression of certain proteins. GSDMD expression was induced by $\mathrm{As}_{2} \mathrm{O}_{3}$ in the GSDMD- and GSDME-negative cell line Bel-7402, while GSDME expression was not (Fig. S4). In addition, the expression of Dnmt3a, Dnmt3b, and Dnmt1 was decreased with an increasing dose of $\mathrm{As}_{2} \mathrm{O}_{3}$, which may be responsible for GSDMD expression in Bel-7402. However, GSDMD expression was not induced in GSDME-positive cell lines (Huh7 and HepG2). Immunoblotting of Dnmt3a, Dnmt3b, and Dnmt1 was performed in Huh7 and HepG2 cells treated with the $\mathrm{As}_{2} \mathrm{O}_{3}$ formulation for $48 \mathrm{~h}$. The results showed that $\mathrm{As}_{2} \mathrm{O}_{3}-\mathrm{NPs}$ and free $\mathrm{As}_{2} \mathrm{O}_{3}$ could reduce the expression of Dnmt3a, Dnmt3b, and Dnmt1, and the effects of $\mathrm{As}_{2} \mathrm{O}_{3}$-NPs were more pronounced (Fig. 3).

Antitumor effect in the Huh7 xenograft nude mouse model The in vivo antitumor effect of various $\mathrm{As}_{2} \mathrm{O}_{3}$ formulations on a mouse tumor model established using Huh7 cells was explored. Huh7 xenograft-bearing mice were treated with $\mathrm{As}_{2} \mathrm{O}_{3}$ or $\mathrm{As}_{2} \mathrm{O}_{3^{-}}$ NPs through intratumoral administration once a week. Free $\mathrm{As}_{2} \mathrm{O}_{3}$ 

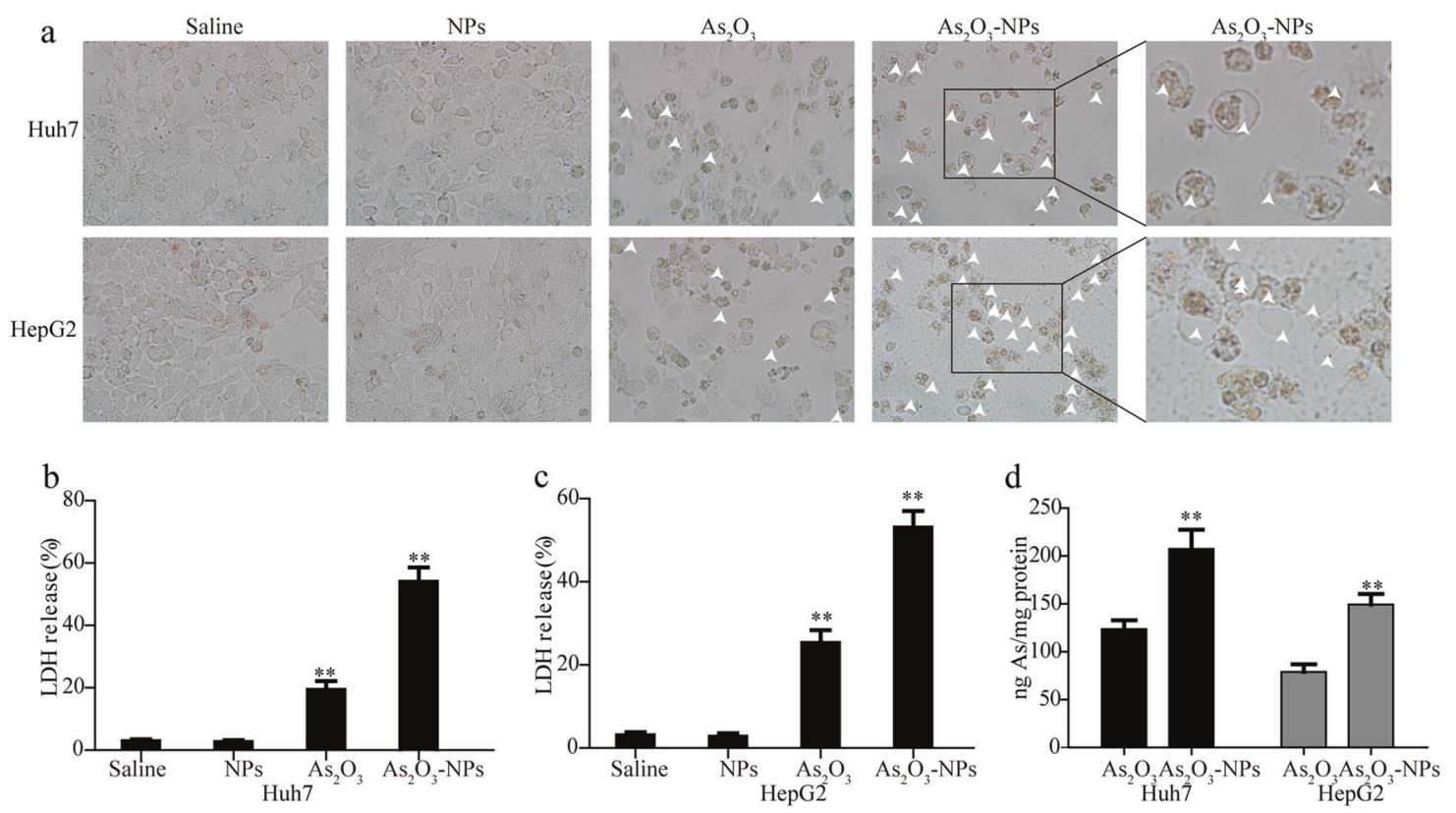

Fig. $2 \mathrm{As}_{2} \mathrm{O}_{3}-\mathrm{NPs}$ induce HCC pyroptosis. Huh7 and HepG2 cells were treated for $48 \mathrm{~h}$ with $4 \mu \mathrm{M}(\mathrm{Huh} 7)$ or $1.5 \mu \mathrm{M}(\mathrm{HepG}) \mathrm{As} \mathrm{O}_{3}$. a Representative microscopic images of Huh7 and HepG2 cells treated with $\mathrm{As}_{2} \mathrm{O}_{3}$ at the indicated concentrations. White arrowheads indicate dying cells with cell membrane blebbing (400x). b, c LDH release assays were used to measure cell membrane destruction. $\mathbf{d}$ Total arsenic uptake was measured by ICP-MS using digested cell pellets. The intracellular arsenic content was normalized to the protein level. The intracellular arsenic content is presented as arsenic (As)/protein (ng/mg). ${ }^{*} p<0.05,{ }^{* *} p<0.01$ compared with control
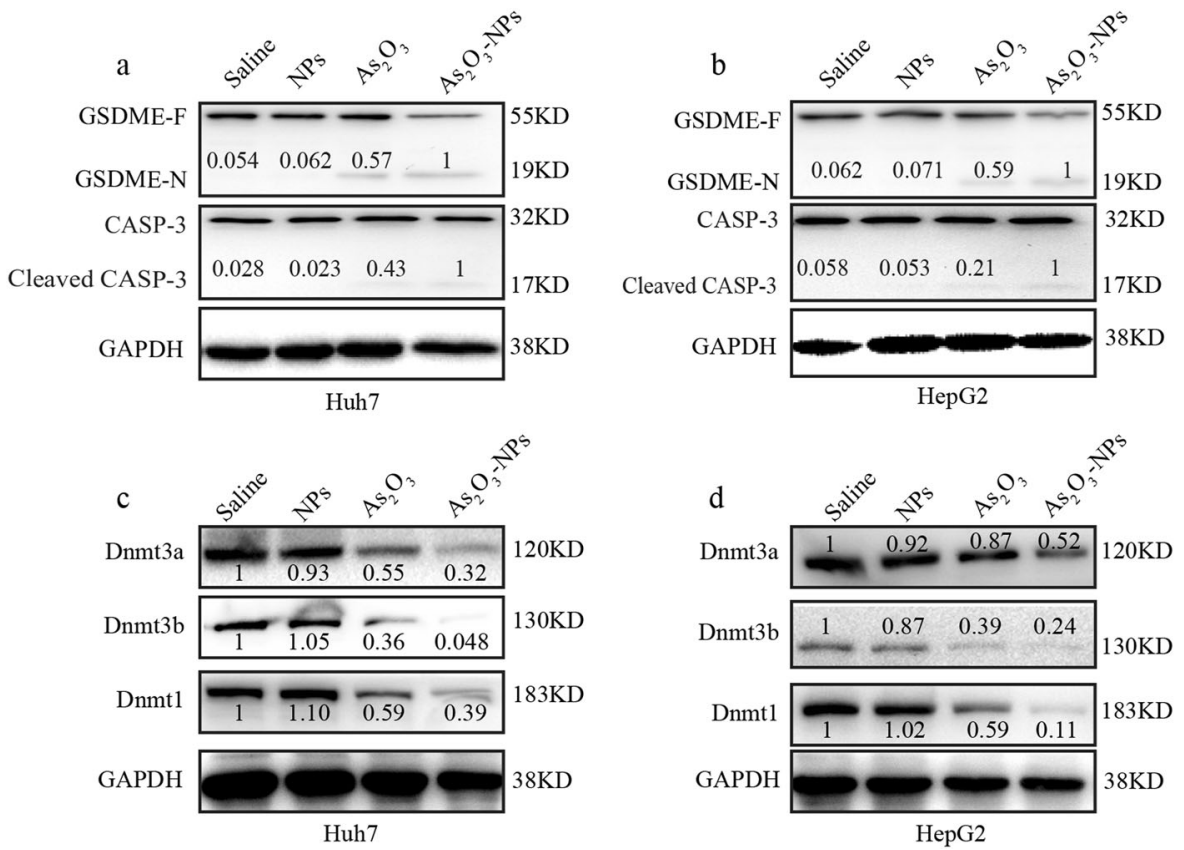

Fig. $3 \mathrm{As}_{2} \mathrm{O}_{3}$ can induce GSDME cleavage. Huh7 and $\mathrm{HepG} 2$ cells were treated for $48 \mathrm{~h}$ with $4 \mu \mathrm{M}$ and $1.5 \mu \mathrm{M}$ As $\mathrm{O}_{3}$, respectively. a GSDME-F (full-length GSDME), GSDME-N (N-terminal-cleaved GSDME), cleaved caspase 3, and caspase 3 levels in Huh7 cells were evaluated by immunoblotting. (b) GSDME-F, GSDME-N, cleaved caspase 3 and caspase 3 levels in HepG2 cells were detected by immunoblotting. c Dnmt3a, Dnmt3b and Dnmt1 levels in Huh7 cells were measured by immunoblotting. d Dnmt3a, Dnmt3b and Dnmt1 levels in HepG2 cells were detected by immunoblotting

moderately inhibited tumor growth, while $\mathrm{As}_{2} \mathrm{O}_{3}-\mathrm{NPs}$ considerably reduced tumor growth (Fig. 4a). Next, the in vivo antitumor activity of different formulations was determined by western blotting. Tumor tissues were homogenized, and proteins were isolated to detect the tumor proliferation marker PCNA by western blotting (Fig. 4d). The protein expression level of PCNA was lower in the $\mathrm{As}_{2} \mathrm{O}_{3}-\mathrm{NP}$ group than in the $\mathrm{As}_{2} \mathrm{O}_{3}$ or saline group. The increased therapeutic efficacy of $\mathrm{As}_{2} \mathrm{O}_{3}$-NPs in vivo may be due to controlled drug release and the prolonged retention time of $\mathrm{As}_{2} \mathrm{O}_{3}$. Taken together, these experimental data clearly indicated the greatly increased therapeutic effect of the nano delivery system based on its in vivo antiproliferative activity. 

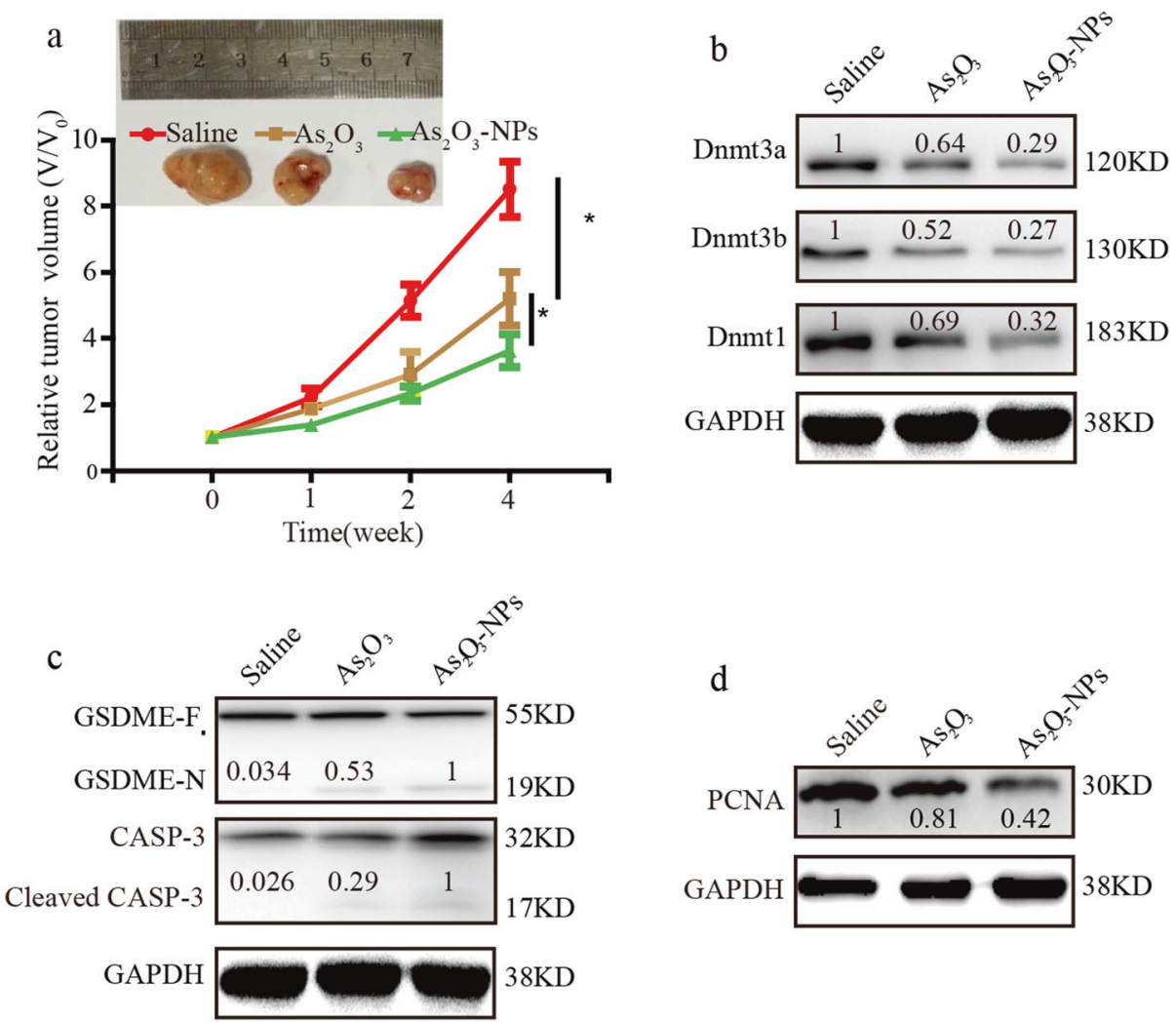

Fig. 4 Anticancer effect in the Huh7 xenograft nude mouse model. a Change in the relative tumor volume of Huh7 xenograft tumors in nude mouse during the treatment period. $\mathbf{b}$ The expression of full-length GSDME (GSDME-F), N-terminal-cleaved GSDME (GSDME-N), caspase 3 and cleaved caspase 3. c The expression of Dnmt3a, Dnmt3b, and Dnmt1. d The expression of PCNA

The protein expression levels of the pyroptosis-related protein GSDME and DNA methyltransferases (Dnmt1, Dnmt3a, and Dnmt3b) in tumor tissues were evaluated by western blotting (Fig. 4) to explore the mechanism of the in vivo antitumor activity of $\mathrm{As}_{2} \mathrm{O}_{3}$-NPs. GSDME-N expression levels were higher in the $\mathrm{As}_{2} \mathrm{O}_{3}-\mathrm{NPs}$ group than in the $\mathrm{As}_{2} \mathrm{O}_{3}$ group, which corresponded with the effects of $\mathrm{As}_{2} \mathrm{O}_{3}-\mathrm{NPs}$ in vitro (Fig. 4c). DNA methyltransferase-related proteins are associated with hepatocarcinogenesis. The protein expression levels of Dnmt1, Dnmt3a, and Dnmt3b were relatively low in the $\mathrm{As}_{2} \mathrm{O}_{3}$-NP group than in the $\mathrm{As}_{2} \mathrm{O}_{3}$ group, a finding that was consistent with the in vitro data (Fig. 4b). The above results showed that $\mathrm{As}_{2} \mathrm{O}_{3}-\mathrm{NPs}$ may have enhanced antitumor effects through GSDME cleavage and downregulation of DNA methyltransferase expression.

\section{Safety evaluation of $\mathrm{As}_{2} \mathrm{O}_{3}$-NPs in vivo}

Considering the side effects of $\mathrm{As}_{2} \mathrm{O}_{3}$, we evaluated the potential effects of $\mathrm{As}_{2} \mathrm{O}_{3}-\mathrm{NPs}$ on major organs. Histopathological changes in the heart, liver, spleen, kidney, and lung were analyzed. No significant morphological changes were observed in these organs (Fig. 5). The above results showed that treatment with $\mathrm{As}_{2} \mathrm{O}_{3}-\mathrm{NPs}$ not only achieved a significant antitumor effect but also had no obvious adverse effects.

\section{DISCUSSION}

Upon systemic injection of an anticancer drug, a small fraction of the drug will reach the solid tumor, and an even smaller amount will penetrate internal tumor tissue and reach the target cells. ${ }^{29,30}$ Local administration allows for the precise delivery of chemical compounds directly to tumor sites. ${ }^{14}$ In this study, we used a PEAL polymer synthesized in our laboratory. Our previous research showed that drug uptake was enhanced by mPEG-PLGA-PLL NPs. ${ }^{19}$ The appropriate size of $\sim 120 \mathrm{~nm}$ and the positive charge of the NPs were responsible for their prompt endocytosis. Thus, mPEG-PLGA-PLL packed with $\mathrm{As}_{2} \mathrm{O}_{3}$ exhibited good therapeutic efficacy.

Arsenic trioxide can downregulate the expression of DNA methyltransferases in cells of various tumors, including HCC. The epigenetic mechanism that has been most intensively studied is the methylation of $\mathrm{CpG}$ dinucleotides, which plays a key role in oncogenic transformation and cell fate determination. Most CpG islands in promoter regions in human cancer are hypermethylated, DNA in general is hypomethylated, and transcriptional silencing of tumor suppressor genes occurs. ${ }^{31-33}$ Dnmt3b and Dnmt3a are involved in de novo DNA methylation; however, Dnmt1 plays a key role in maintaining DNA methylation. The hypermethylation of $\mathrm{CpG}$ islands has recently been implicated in hepatocarcinogenesis through the epigenetic silencing of tumor suppressor genes. Dnmt1 is the main enzyme responsible for copying methylation patterns after DNA replication. ${ }^{34}$ In HCC patients, elevated Dnmt1 protein expression is related to a significantly lower survival rate compared with decreased Dnmt1 protein expression. Thus, increased Dnmt1 protein expression may play an important role in the malignant progression of HCC, which indicates that it is associated with a poor prognosis in HCC patients. ${ }^{35}$ In this study, $\mathrm{As}_{2} \mathrm{O}_{3}$-NPs also reduced the expression of DNA methyltransferases in vivo. ${ }^{36,37}$ PCNA plays an important role in DNA replication, and $\mathrm{As}_{2} \mathrm{O}_{3}-\mathrm{NPs}$ decreased PCNA expression. The Dnmt1-PCNA interaction could lead to the prompt remethylation of newly biosynthesized and naked DNA before assembly into chromatin. ${ }^{38}$ Therefore, $\mathrm{As}_{2} \mathrm{O}_{3}$-NPs may show enhanced therapeutic efficacy by decreasing the expression of PCNA and the Dnmt1-PCNA interaction (Fig. 6). 

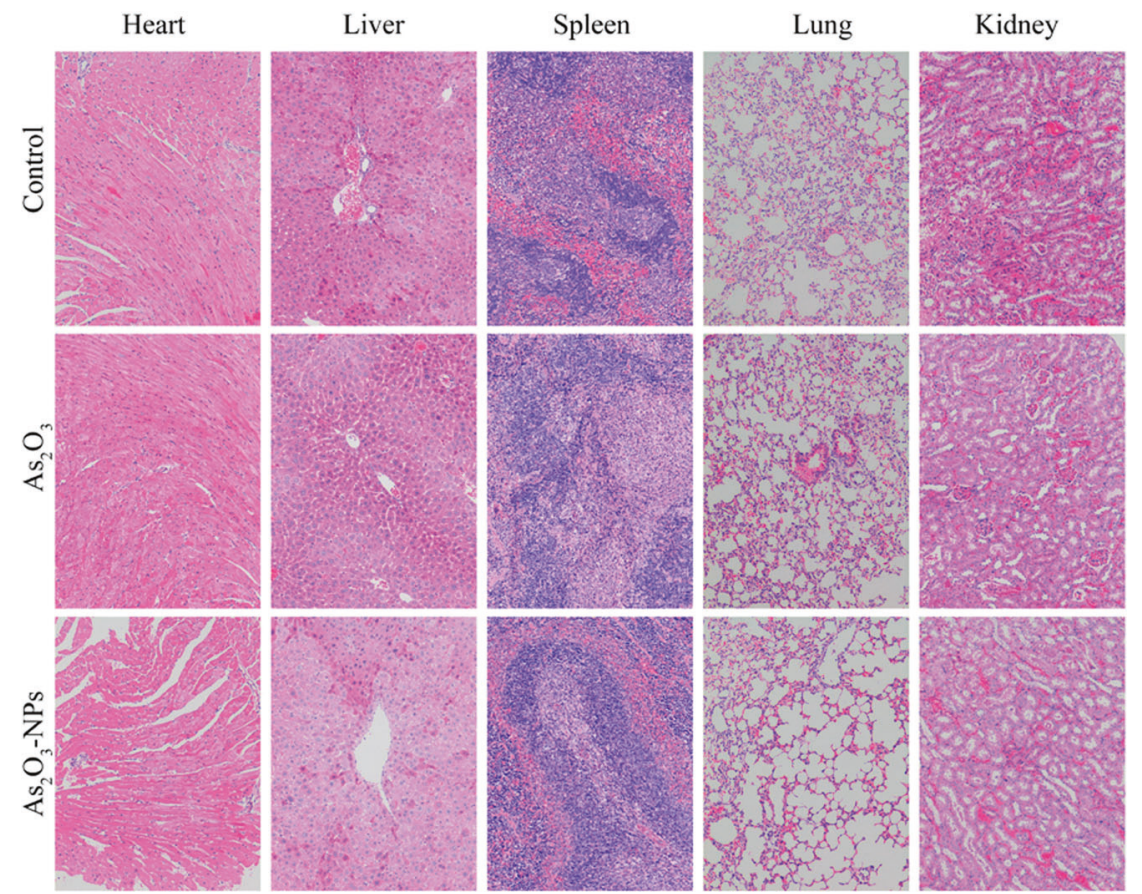

Fig. 5 Safety evaluation of $\mathrm{As}_{2} \mathrm{O}_{3}-\mathrm{NPs}$ in vivo. H\&E histology images of heart, liver, spleen, lung, and kidney from tumor-bearing mice after different treatments for four weeks (100X)

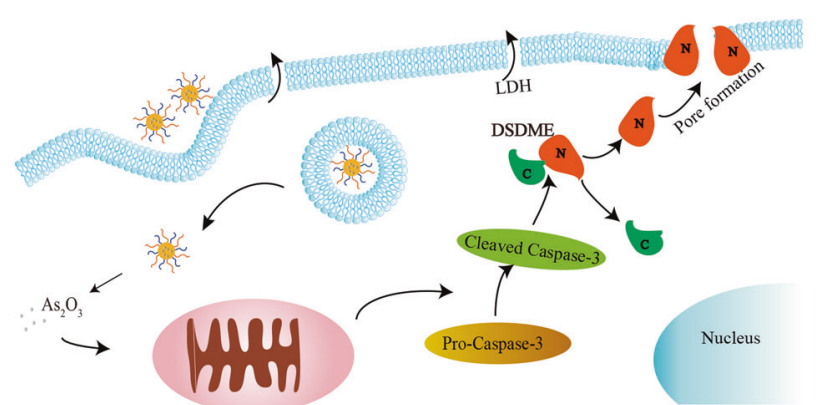

Fig. 6 Mechanisms of pyroptosis induced by $\mathrm{As}_{2} \mathrm{O}_{3}-\mathrm{NPs}$ in $\mathrm{HCC}$. GSDME cleavage is triggered by the caspase 3 activation after $\mathrm{As}_{2} \mathrm{O}_{3}-\mathrm{NP}$ treatment. The $\mathrm{N}$-terminal domain of GSDME is released and enters the membrane. Next, GSDME-N functions in membrane pore formation, thereby resulting in pyroptosis of $\mathrm{As}_{2} \mathrm{O}_{3^{-}}$ treated cells

Apoptosis and programmed necrosis have distinct phenotypes. Apoptosis is a universal method of nonlytic cell death, and apoptotic cells have an immunologically 'silent' phenotype. Necrotic cells swell and release inflammatory factors, such as $\mathrm{IL}-1 \beta$, leading to lytic cell death. ${ }^{37}$ Pyroptosis is a type of programmed necrosis that depends on GSDME or GSDMD cleavage and is characterized by membrane pore formation, cell bulging, bleb formation, cytolysis, and the release of cytoplasmic content. ${ }^{25}$ The results of our study indicated that $\mathrm{As}_{2} \mathrm{O}_{3}$ induced typical pyroptosis, characterized by large membrane blebs and $\mathrm{LDH}$ release from HCC cells. Moreover, the $\mathrm{LDH}$ release assay indicated membrane disruption in $\mathrm{As}_{2} \mathrm{O}_{3}$-treated $\mathrm{HCC}$ cells. GSDMD has been demonstrated to promote membrane pore formation and induce pyroptosis. $\mathrm{As}_{2} \mathrm{O}_{3}$ induced GSDMD expression and pyroptosis in Bel-7402 cells, perhaps by influencing the methylation of CpG islands on GSDMD through decreased Dnmt1, Dnmt3a, and Dnmt3b expression.

Recently, GSDME was shown to have the same function as GSDMD in pyroptosis. The GSDME gene was originally found to result in autosomal dominant hearing loss $(\mathrm{HL})$. GSDME-related $\mathrm{HL}$ is due to a highly specific gain-of-function mutation that increases the activity of GSDME, and the expression of this specific mutant protein causes pyroptosis. Apart from its involvement in $\mathrm{HL}$, GSDME functions as a tumor suppressor. Epigenetic mechanisms result in inactivation of the GSDME gene in many types of cancer, including colorectal, breast, and gastric cancer. While little is known concerning its role in HCC, HepG2 cells express detectable GSDME protein, resulting in the formation of GSDME-N after treatment with cytochrome c. Our study indicated that GSDME expression levels were relatively high in Huh7 and HepG2 cells. $\mathrm{As}_{2} \mathrm{O}_{3}$ induced the cleavage of GSDME. The expression levels of GSDME-N were significantly higher after $\mathrm{As}_{2} \mathrm{O}_{3}-\mathrm{NP}$ treatment than after $\mathrm{As}_{2} \mathrm{O}_{3}$ treatment alone. GSDME activation in chemicalinduced pyroptosis occurs downstream of caspase 3, and GSDME cleavage depends on caspase 3 activation to induce pyroptosis.

In summary, we report for the first time that $\mathrm{As}_{2} \mathrm{O}_{3}$ treatment can trigger pyroptosis in GSDME-expressing HCC cells. Furthermore, our study showed that activated caspase 3 cleaved GSDME to release the free N-terminal domain, which then triggered pyroptosis (Fig. 6). These data provide new insights into the action of $\mathrm{As}_{2} \mathrm{O}_{3}$ in $\mathrm{HCC}$ cells, which could be exploited for therapeutic purposes.

\section{MATERIALS AND METHODS}

Materials

mPEG-PLGA-PLL (PEAL) was prepared as previously described. ${ }^{19}$ Arsenic trioxide was kindly provided by Harbin YIDA Pharmaceutical Co., Ltd (Heilongjiang, China). Protein determination kits and RIPA lysis buffer were obtained from Beyotime Institute of Biotechnology. Antibodies against Dnmt1, Dnmt3a, Dnmt3, and GSDME were purchased from Abcam (Shanghai, China), and GSDMD monoclonal antibodies were supplied by Sigma (USA). Caspase 3, GAPDH, and PCNA monoclonal antibodies were supplied by Cell Signaling Technology (Shanghai, China).

Preparation and characterization of $\mathrm{As}_{2} \mathrm{O}_{3}$-PEAL nanoparticles mPEG-PLGA-b-PLL NPs were prepared as previously described. A double-emulsion method was used to prepare $\mathrm{As}_{2} \mathrm{O}_{3}-\mathrm{PEAL} N P s$ 
$\left(\mathrm{As}_{2} \mathrm{O}_{3}\right.$-mPEG-PLGA-b-PLL nanoparticles) as follows. Briefly, a 0.2$\mathrm{ml}$ aqueous solution of $\mathrm{As}_{2} \mathrm{O}_{3}(5 \mathrm{mg} / \mathrm{ml})$ was added into $0.5 \mathrm{ml}$ of dichloromethane containing $10 \mathrm{mg}$ of PEAL copolymer and emulsified with an ultrasonic processor at $400 \mathrm{~W}$ for $2 \mathrm{~min}$. Next, the above emulsion was added to $1.8 \mathrm{ml}$ of pluronic F68 water solution $(1 \mathrm{mg} / \mathrm{ml})$ and emulsified at $400 \mathrm{~W}$ for $2 \mathrm{~min}$. Then, the resulting mixture was stirred at room temperature to remove the organic phase. The size distribution and zeta potential of the NPs were determined with a Zetasizer IV analyzer (Malvern Zetasizer Nano ZS90, UK). Morphological evaluation of $\mathrm{As}_{2} \mathrm{O}_{3}-\mathrm{PEAL}$ NPs was conducted by TEM. The loading capacity (DL\%) and encapsulation efficiency (EE\%) of $\mathrm{As}_{2} \mathrm{O}_{3}$ in $\mathrm{As}_{2} \mathrm{O}_{3}$-PEAL NPs were measured by inductively coupled plasma emission spectroscopy (ICP) combined with ultracentrifugation ( $35 \mathrm{~min}, 18,000 \mathrm{r} / \mathrm{min}$ ). Unencapsulated $\mathrm{As}_{2} \mathrm{O}_{3}$ in the supernatant was quantified using the ICP method. In vitro $\mathrm{As}_{2} \mathrm{O}_{3}$ release was assayed according to previously published procedures.

Assessment of pyroptotic cell death under optical microscopy Huh7 and HepG2 cells were observed for pyroptosis. Huh7 and HepG2 cells were seeded in a 6 -well plate $\left(2.25 \times 10^{5} /\right.$ well $)$ and cultured for $24 \mathrm{~h}$; then, the medium was removed, and different concentrations of drug ( $4 \mu \mathrm{M}$ for Huh7 cells, $1.5 \mu \mathrm{M}$ for HepG2 cells) were added for $48 \mathrm{~h}$. Representative images were obtained using a microscope (Olympus IX71, Japan).

The $\mathrm{LDH}$ release assay and cellular uptake of arsenic

The $\mathrm{LDH}$ release into the medium of cells treated with different formulations, similar to those described above, was determined by an LDH Cytotoxicity Assay Kit (Beyotime). The absorbance was then detected at $450 \mathrm{~nm}$. The release of LDH into the cell culture medium was calculated as a percentage of total $\mathrm{LDH}$ release after cell lysis. For the analysis of arsenic influx, two HCC cell lines were treated with the indicated concentration of drug $(4 \mu \mathrm{M}$ for Huh7 cells, $1.5 \mu \mathrm{M}$ for HepG2 cells) for $24 \mathrm{~h}$, according to previous reports. $^{39}$

Western blotting analysis of pyroptosis- and DNMT-related proteins in vitro

Total protein was extracted from tumor cells exposed to different treatments. A BCA protein determination kit was used to measure the protein concentration. Ten micrograms of protein from each sample was loaded and separated by SDS-PAGE (10-15\%). After transfer to a PVDF (Polyvinylidene Fluoride) membrane, the proteins were analyzed using Dnmt1, Dnmt3a and Dnmt3b, GSDME, GSDMD, caspase 3, and GAPDH antibodies. All monoclonal antibodies were diluted 1:1000. After incubation with the corresponding HRP-conjugated secondary antibodies (1:1000), protein bands were detected. The GAPDH expression level was used as a standard to normalize the expression of the other proteins.

In vivo antitumor activity of $\mathrm{As}_{2} \mathrm{O}_{3}-\mathrm{NPs}$

This study was performed in accordance with the guidelines approved by the Animal Care and Use Committee of the Shanghai Cancer Institute. The xenograft tumor model was established by the subcutaneous inoculation of $2 \times 10^{6}$ Huh7 cells mixed with Matrigel into the backs of nude mice. After the tumor volume reached $\sim 200 \mathrm{~mm}^{3}$, the mice were randomized into three groups. The three groups received intratumoral injections of saline, free $\mathrm{As}_{2} \mathrm{O}_{3}$, or $\mathrm{As}_{2} \mathrm{O}_{3}-\mathrm{NPs}$ (all $\mathrm{As}_{2} \mathrm{O}_{3}$ formulations were equivalent to $2 \mathrm{mg} / \mathrm{kg}$ body weight). Each formulation was administered four times at 1-week intervals. The tumor volume was measured before every injection. The tumor dimensions were measured with a caliper to monitor tumor growth. The tumor volume $(V)$ was estimated based on the following equation: $V=$ [length $\times$ (width) $\left.)^{2}\right] / 2$.
Safety evaluation of $\mathrm{As}_{2} \mathrm{O}_{3}-\mathrm{NPs}$

Mice in each group were randomly chosen and sacrificed after treatment for 4 weeks. Next, the major organs, including the heart, liver, spleen, lung, and kidney, were removed and fixed in $4 \%$ formaldehyde for $48 \mathrm{~h}$. Then, the samples were embedded in paraffin, sectioned, stained with hematoxylin and eosin (H\&E) and observed with a digital microscope.

Statistical analysis

The results are presented as the mean \pm SD. The level of significance was determined by one-way ANOVA (analysis of variance) using SPSS software (version 17.0; IBM Inc., Chicago, IL, USA). A $P$ value $<0.05$ was considered statistically significant, and $P<0.01$ indicated a highly significant difference.

\section{DATA AVAILABILITY}

All data generated or analyzed during this study are included in this published article and its supplementary information files.

\section{ACKNOWLEDGEMENTS}

This research was supported by the National Natural Science Foundation of China (Nos. 81572999, 81771839, 21807071, and 81773272), the Foundation of Shanghai Municipal Health Commission (No. 201640091), and the State Key Laboratory of Oncogenes and Related Genes (No. 91-17-20).

\section{AUTHOR CONTRIBUTIONS}

M.S. and Y.D. participated in the experimental design and critical revision of the paper; J.H., W.W., and Y.D. performed the in vivo experiments and data analysis and drafted the paper; J.H. and L.D. performed the in vitro and molecular biology experiments; Y.D. and Z.W. synthesized the $\mathrm{As}_{2} \mathrm{O}_{3}$ nanoparticles and performed the DLS measurements; and all authors have given their final approval for the submission of this paper.

\section{ADDITIONAL INFORMATION}

The online version of this article (https://doi.org/10.1038/s41392-019-0062-9) contains supplementary material, which is available to authorized users.

Competing interests: The authors declare no competing interests.

\section{REFERENCES}

1. Forner, A., Reig, M. \& Bruix, J. Hepatocellular carcinoma. Lancet 391, 1301-1314 (2018).

2. Teran V. A., Wilson B. B., Guffey D. J. Flexural eruption associated with arsenic trioxide therapy in a patient with acute promyelocytic leukemia. JAMA Dermatol. https://doi.org/10.1001/jamadermatol.2018.5258 (2019).

3. Spinello, I. et al. The small-molecule compound AC-73 targeting CD147 inhibits leukemic cell proliferation, induces autophagy and increases the chemotherapeutic sensitivity of acute myeloid leukemia cells. Haematologica 104, 973-985 (2019).

4. Zhang, X. Y. et al. Endoplasmic reticulum stress mediates the arsenic trioxideinduced apoptosis in human hepatocellular carcinoma cells. Int. J. Biochem. Cell Biol. 68, 158-165 (2015).

5. Eyvani, H. et al. Arsenic trioxide induces cell cycle arrest and alters DNA methylation patterns of cell cycle regulatory genes in colorectal cancer cells. Life Sci. 167, 67-77 (2016).

6. Qiu, Y. et al. Arsenic trioxide reverses the chemoresistance in hepatocellular carcinoma: a targeted intervention of 14-3-3eta/NF-kappaB feedback loop. J. Exp. Clin. Cancer Res. 37, 321 (2018).

7. Chi, X. et al. Targeted arsenite-loaded magnetic multifunctional nanoparticles for treatment of hepatocellular carcinoma. Nanotechnology 30, 175101 (2019).

8. Zhao, Z. et al. Silica nanovehicles endow arsenic trioxide with an ability to effectively treat cancer cells and solid tumors. J. Mater. Chem. B2, 6313-6323 (2014).

9. Akhtar, A., Xiaoyan Wang, S., Ghali, L., Bell, C. \& Wen, X. Recent advances in arsenic trioxide encapsulated nanoparticles as drug delivery agents to solid cancers. J. Biomed. Res. 31, 177-188 (2017). 
10. Fei, W. et al. RGD conjugated liposome-hollow silica hybrid nanovehicles for targeted and controlled delivery of arsenic trioxide against hepatic carcinoma. Int. J Pharm. 519, 250-262 (2017).

11. Nuhn, L. et al. Nanoparticle-conjugate TLR7/8 agonist localized immunotherapy provokes safe antitumoral responses. Adv. Mater. 30, e1803397 (2018).

12. Wang, $C$. et al. In situ formed reactive oxygen species-responsive scaffold with gemcitabine and checkpoint inhibitor for combination therapy. Sci. Transl. Med. 10. https://doi.org/10.1126/scitranslmed.aan3682 (2018).

13. Kim, D. Y. et al. Synergistic anti-tumor activity through combinational intratumoral injection of an in-situ injectable drug depot. Biomaterials 85, 232-245 (2016).

14. Xu, Y. et al. Preparation of a paclitaxel-loaded cationic nanoemulsome and its biodistribution via direct intratumoral injection. Colloids Surf. B Biointerfaces 142, 81-88 (2016).

15. Shen, M., Xu, Y. Y., Sun, Y., Han, B. S. \& Duan, Y. R. Preparation of a thermosensitive gel composed of a mPEG-PLGA-PLL-CRGD nanodrug delivery system for pancreatic tumor therapy. ACS Appl. Mater. Interfaces 7, 20530-20537 (2015).

16. Aggarwal, U., Goyal, A. K. \& Rath, G. Development of drug targeting and delivery in cervical cancer. Curr. Cancer Drug Targets 18, 792-806 (2018).

17. Guo, G. et al. Preparation of curcumin loaded poly(epsilon-caprolactone)-poly (ethylene glycol)-poly(epsilon-caprolactone) nanofibers and their in vitro antitumor activity against Glioma 9L cells. Nanoscale 3, 3825-3832 (2011).

18. Teng, Y. et al. Enhanced delivery of PEAL nanoparticles with ultrasound targeted microbubble destruction mediated siRNA transfection in human MCF-7/S and MCF-7/ADR cells in vitro. Int. J. Nanomed. 10, 5447-5457 (2015).

19. Liu, P., Yu, H., Sun, Y., Zhu, M. \& Duan, Y. A mPEG-PLGA-b-PLL copolymer carrier for adriamycin and siRNA delivery. Biomaterials 33, 4403-4412 (2012).

20. He, Z. et al. The biocompatibility evaluation of mPEG-PLGA-PLL copolymer and different LA/GA ratio effects for biocompatibility. J. Biomater. Sci. Polym. Ed. 25, 943-964 (2014).

21. Zhang, X. et al. Arsenic trioxide induces G2/M arrest in hepatocellular carcinoma cells by increasing the tumor suppressor PTEN expression. J. Cell. Biochem. 113, 3528-3535 (2012).

22. Shi, J. et al. Cleavage of GSDMD by inflammatory caspases determines pyroptotic cell death. Nature 526, 660-665 (2015).

23. Sborgi, L. et al. GSDMD membrane pore formation constitutes the mechanism of pyroptotic cell death. EMBO J. 35, 1766-1778 (2016).

24. Rogers, C. et al. Cleavage of DFNA5 by caspase- 3 during apoptosis mediates progression to secondary necrotic/pyroptotic cell death. Nat. Commun. 8, 14128 (2017).

25. Wang, Y. et al. Chemotherapy drugs induce pyroptosis through caspase-3 cleavage of a gasdermin. Nature 547, 99-103 (2017).

26. Lu, H. et al. Molecular targeted therapies elicit concurrent apoptotic and GSDME-dependent pyroptotic tumor cell death. Clin. Cancer Res. 24, 6066-6077 (2018).

27. Zhou, B. et al. Tom 20 senses iron-activated ROS signaling to promote melanoma cell pyroptosis. Cell Res. 28, 1171-1185 (2018).
28. Wang, Y. et al. GSDME mediates caspase-3-dependent pyroptosis in gastric cancer. Biochem. Biophys. Res. Commun. 495, 1418-1425 (2018).

29. Popilski, H., Abtew, E., Schwendeman, S., Domb, A. \& Stepensky, D. Efficacy of paclitaxel/dexamethasone intra-tumoral delivery in treating orthotopic mouse breast cancer. J. Control. Release 279, 1-7 (2018).

30. Larsson, M., Huang, W. T., Liu, D. M. \& Losic, D. Local co-administration of genesilencing RNA and drugs in cancer therapy: state-of-the art and therapeutic potential. Cancer Treat. Rev. 55, 128-135 (2017).

31. Pfeifer G. P. Defining driver DNA methylation changes in human cancer. Int. J. Mol. Sci. 19. https://doi.org/10.3390/ijms19041166 (2018).

32. Stirzaker, C. et al. Methyl-CpG-binding protein MBD2 plays a key role in maintenance and spread of DNA methylation at CpG islands and shores in cancer. Oncogene 36, 1328-1338 (2017).

33. Ammerpohl, O. et al. Distinct DNA methylation patterns in cirrhotic liver and hepatocellular carcinoma. Int. J. Cancer 130, 1319-1328 (2012).

34. Miremadi, A., Oestergaard, M. Z., Pharoah, P. D. \& Caldas, C. Cancer genetics of epigenetic genes. Hum Mol. Genet. 16(Spec No 1), R28-R49 (2007).

35. Saito, Y. et al. Increased protein expression of DNA methyltransferase (DNMT) 1 is significantly correlated with the malignant potential and poor prognosis of human hepatocellular carcinomas. Int. J. Cancer 105, 527-532 (2003).

36. Vertino, P. M. et al. DNMT1 is a component of a multiprotein DNA replication complex. Cell Cycle 1, 416-423 (2002).

37. Ally, A., Balasundaram, M., Carlsen, R., Chuah, E., Clarke, A. \& Dhalla, N. et al. Comprehensive and Integrative Genomic Characterization of Hepatocellular Carcinoma. Cell 169, 1327-1341. https://doi.org/10.1016/j.cell.2017.05.046 (2017).e1323.

38. Subramaniam, D., Thombre, R., Dhar, A. \& Anant, S. DNA methyltransferases: a novel target for prevention and therapy. Front. Oncol. 4, 80 (2014).

39. Zhang, Q., Vakili, M. R., Li, X. F., Lavasanifar, A. \& Le, X. C. Terpolymer micelles for the delivery of arsenic to breast cancer cells: the effect of chain sequence on polymeric micellar characteristics and cancer cell uptake. Mol. Pharm. 13, 4021-4033 (2016).

(i) Open Access This article is licensed under a Creative Commons Attribution 4.0 International License, which permits use, sharing, adaptation, distribution and reproduction in any medium or format, as long as you give appropriate credit to the original author(s) and the source, provide a link to the Creative Commons license, and indicate if changes were made. The images or other third party material in this article are included in the article's Creative Commons license, unless indicated otherwise in a credit line to the material. If material is not included in the article's Creative Commons license and your intended use is not permitted by statutory regulation or exceeds the permitted use, you will need to obtain permission directly from the copyright holder. To view a copy of this license, visit http://creativecommons. org/licenses/by/4.0/.

(c) The Author(s) 2019 